\title{
Co-Teaching in EFL Classroom: The Promising Model
}

\author{
Dalal E. Boland ${ }^{1}$, Khalifa B. Alkhalifa ${ }^{1} \&$ Mohammad A. Al-Mutairi ${ }^{1}$ \\ ${ }^{1}$ Language Center, College of Basic Education, Public Authority for Applied Education and Training, Kuwait \\ Correspondence: Mohammad A. Al-Mutairi, Language Center, College of Basic Education, Kuwait.
}

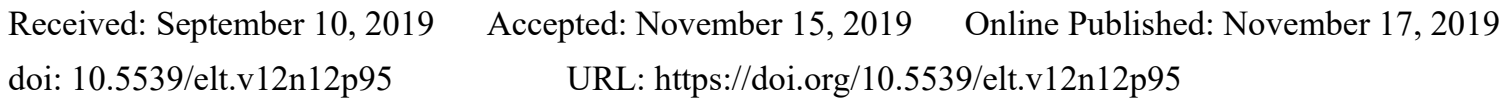

\begin{abstract}
The research aimed to examine whether co-teaching in EFL classrooms could have positive impacts on students' learning outcomes and their overall academic performance, including the improvement of the four language skills (listening, speaking, reading and writing). The experiment of the study was conducted throughout the summer course of 2018 for six weeks at the College of Basic Education with a class of 24 female students. The classes were held every day for one hour and twenty minutes. A simultaneous comparison between two classrooms was conducted in which one class was taught by a single instructor (the control group), and the other class was based on co-teaching (the experimental group). The two groups were taught by Khalifa AlKhalifa and Dalal Boland who acted as "one brain in two bodies" in their EFL classroom. Numerous sittings took place before each class to discuss how the lesson was to be divided between them and to reach an agreement on several matters, such as which instructor would deliver the lesson, which activities were to be solved, and how the second instructor would be beneficial in providing support and assistance to students throughout the entire class period.

Moreover, both instructors established goals and objectives for every lesson and made sure that students meet those objectives by the end of every class period. Well-established plans and ideas on how to grasp those targets were agreed upon throughout the implementation of different materials to cover the content of the syllabus. After the summer semester came to an end and when the class average of both classes was compared, the results proved that the students who were in a co-taught classroom showed a significant improvement in their academic performance, whereas students who were taught solely by one instructor showed less improvement in their overall academic skills. This shows that well-planned co-teaching programs could lead to better student support within classroom settings, which consequently leads to improved EFL learning.
\end{abstract}

Keywords: co-teaching, team teaching, ESL, EFL, TESOL

\section{Introduction}

It is agreed upon that teaching is considered a complex process that takes place in academic settings (Aliakbari and Nejad, 2010). Teachers should use the appropriate techniques and strategies, along with the right methods and approaches, to get the message across to all students based on the students' preferred learning styles. With that in mind, teaching might even be considered more complex if it is being delivered in a second/foreign language. For this reason, teachers should always look for the best possible teaching methodologies for their ESL/EFL classrooms to improve their students' language education. Co-teaching could be one of the pioneering options that might help in combating underachievement in EFL. It is traditionally defined as the collaboration between general and special education (SPED) teachers for all of the teaching responsibilities of all of the students assigned to a classroom (Gately \& Gately, 2001).In other words, in a traditional classroom, only one teacher is in charge of teaching the content of the syllabus, whereas a co-teaching classroom setting makes two teachers responsible for the class. On this note, co-teaching is explained as two teachers jointly being responsible for a class, and they "plan teaching together, plan instruction together, share teaching duties and design collectively all teaching aids." No matter what strategy of co-teaching is implemented in the class, the dual teachers are expected to work collaboratively to alleviate the workload burdens on teachers especially in terms of curriculum content.

The co-teachers are expected to have respect for one another, display trust, and explicitly describe the co-teaching strategies that they are going to use. Some of the strategies that were implemented in this study are that one teaches while one observes, and also team teaching, in which both teachers are available to assist 
students and answer questions.

Maduako and Oyatogum (2015) define team-teaching as the ability of people working together to achieve a common goal, while team players are high achievers in the team "whose main preoccupation is to see that teams achieve their stated objectives." The team of teachers is in a constant search for ways to teach that will engage the students and make them "maintain their interest and enhance learning concepts" (Gillespie \& Israetel, 2008). The aim of this paper, therefore, is to see whether co-teaching has a positive impact on students' academic performances in a foreign/second language class or not.

\section{Purpose of the Study and the Research Question}

As mentioned earlier, the present study aims to explore the relationship between the engagement of co-teaching and students' overall academic performances. To investigate if whether co-teaching can be a promising method to improve EFL learning or not. In other words, the study tries to get answers to the following question: Does co-teaching improve EFL students' achievement?

\section{Importance of the Study}

Besides the researcher's personal interest in developing and improving the ELT in the College of Basic Education, the findings of this study will provide some insights and information towards opening the door for new foreign language teaching methodology.

In fact, due to the shortage of empirical studies examining EFL co-teaching, this study takes on a pioneering role. Therefore this study could provide the basis for researchers for future studies in EFL co-teaching methods.

\section{Review of Literature}

As EFL students differ in background, motivation, and personal attributes, they also differ in ways they prefer to learn. Some students prefer learning with visual aids, while others prefer learning aurally, verbally, or through kinesthetic activities. As a result, EFL teachers should employ various teaching strategies in their instruction in order to get a meaningful as well as a useful EFL learning. Methods can be practiced either by a single teacher or a team of teachers if they are in charge of the lesson, which is known as co-teaching.

Aliakbari and Nejad (2013) define co-teaching as "The collaborative practice by two teachers to plan, teach, and evaluate the educational program." In other words, it is when dual teachers work together for the purpose of better instruction. In co-teaching, teachers aim to come up with different methods and approaches to deliver the syllabus content and enhance students' academic performances. However, in order to conduct a successful co-teaching, EFL teachers should employ different tasks such as outlining, and managing plus presentation, and evaluation (Aliakbari \& Bazyar, 2012). Moreover, within the harmonious professionalism that both EFL teachers exchange, they will be exposed to many advantages; for example, "division of labor, flexibility, opportunity to learn from each other, and partnership" (Aliakbari \& Nejad, 2010). Students will benefit from the broader level of experience, complementary styles, and enhanced classroom teaching dynamic. Likewise, effective co-teachers are characterized to be tolerant, responsible for all students, and able to establish a positive relationship with one another. There are five strategies to employ co-teaching in the educational structure, and they are labeled as "one teaches, one observes," "parallel teaching," "station teaching," "alternative teaching," and "team teaching" (as shown in Table 1) (Bacharach, Heck, \& Dahlberg, 2008). Murawski and Swanson (2001) conducted a meta-analysis co-teaching research and concluded that the implementation of co-teaching strategies had positive effects on their students' outcomes in the area of reading comprehension and language art. Moreover, the engagement of the strategies mentioned earlier in the learning process could be represented by "two are better than one" in classrooms (Gately, 2005).

Table 1. The seven strategies of co-teaching

\begin{tabular}{ll}
\hline Strategy & Definition/ Application \\
\hline $\begin{array}{l}\text { One teaches, One } \\
\text { observes }\end{array}$ & $\begin{array}{l}\text { When one teacher has dominant pedagogical responsibilities and the other teacher } \\
\text { observes the behavior of students. }\end{array}$ \\
$\begin{array}{l}\text { One teaches, One } \\
\text { drift }\end{array}$ & $\begin{array}{l}\text { Is an expansion of one teach, one observes. One teacher is responsible for teaching the } \\
\text { students while the other teacher provides assistance to students. }\end{array}$ \\
Station Teaching & $\begin{array}{l}\text { When instructional content is divided between the two teachers formulating stations in } \\
\text { which students shift from one station to the other. }\end{array}$
\end{tabular}

Alternative

Teaching

When both teachers provide two different approaches in teaching the same content. 
Team Teaching

Parallel Teaching

Supplemental Teaching
When both teachers are simultaneously involved in teaching the content of the lesson.

When the class is divided into two groups and each teacher is responsible for teaching one group.

This strategy allows one teacher to work with slow learners to reach their normal grade level, while the other teacher works with the advanced students.

When it comes to English language learners, it is important to note that the language is not "soaked up" (Haynes, 2016). The learner must understand the input which is provided by the teacher(s) in order to produce an output in the language (Krashen, 1981).Furthermore, when it comes to language learning, the teacher(s) should connect the content of their lessons to the students' prior knowledge in consideration of the schema of the EFL learners (Haynes, 2016). In a co-teaching context, both teachers collaborate, have equal responsibilities, and decrease student-teacher ratios within the same physical space (Haynes, 2016). In other words, co-teaching is an asset to language teachers because it "provides opportunities for the exhibition of multiple skills. It is more result-oriented, and goals better are achieved when a team strategy is employed" (Maduako and Oyatogum, 2015). Furthermore, some of the advantages of co-teaching, specifically in the team teaching strategy, is the complementary skills shown through a variety of methods, providing more student-support, and adding better supervision to the class (Maduako and Oyatogum 2015).

\section{Methodology}

The study is an attempt to examine the impact of co-teaching on EFL students' achievement. The researchers divided their class into two groups. The first cohort was taught by a sole teacher (the control group), and the second one was enrolled in a co-teaching method (the experimental group). At the end of the summer course, their grades were examined by a t-test, and their results were compared to see the differences between the two groups.

\subsection{The Participants}

The participants of this study were two EFL teachers representing the co-teaching staff and two groups of 24 female students who were enrolled in Academic English 1, which is a compulsory module for all students and a prerequisite for Academic English 2. The students were all female, with ages varying from 18-29.

\subsection{Instruments and Materials}

The central material used in the current study was an English textbook, the 5th edition, published by Keith Folse and used in the EFL classroom to teach Academic English at the College of Basic Education. The textbook contained several chapters about different types of essays and detailed explanations on various subjects-from how to write different types of essays to how to do research, paraphrasing, summarizing, and grammar. The other important instruments used in this study were a projector and a computer with internet access. All of the materials and instruments were used in both classrooms.

\section{Procedures}

The research was conducted to investigate whether co-teaching has a positive effect on students' achievement. The experiment lasted for six weeks and was held every day on a period of one hour and 20 minutes in the summer course of 2018. Throughout the experiment, two simultaneous classrooms took place in which class A was taught solely by a single instructor (the control group), and class B was taught by dual teachers (the experimental group).

In both groups, the book was the main material used along with different comprehension passages to advance students' comprehension level. Since class A is described to be taught only by a single instructor, the experiment here focused on class B because it was co-taught throughout the whole summer semester. The co-teachers in class B used different teaching strategies to deliver the content of the syllabus. Some of the co-teaching strategies were one teaches, one observes; one teaches, one drift; alternative teaching; and team teaching. Before each class period, the dual teachers sat together to decide which strategy was going to be implemented in the lesson. There was a time when the lesson was taught by one teacher and the other teacher observed students' behaviors, and a time when both teachers were involved in teaching the class at the same time. Moreover, when both teachers exchanged roles following the same strategy, students were exposed to different approaches in receiving the same content, which is called the alternative teaching strategy in co-teaching.

Along with that, in class B, one teacher was responsible for following the direct instructions while the other teacher used meaningful task-based instruction implementing common current topics that were associated with 
the students' lives like discussing fashion, cafes and mall shopping. At the end of the experiment, both groups were assessed with the same formal assessments: mid-terms and a final exam. A t-test was used to measure the students' achievement and improvement in reading and writing skills. The two groups were assessed with the same rubric.

\section{Results and Discussion}

In Levene's Test for Equality of Variances, since $p<.05$, we can reject the null hypothesis stating that we assume the variance of students' results between a co-teaching classroom and a regular classroom is not equal. In support of our claim, an independent-samples t-test was conducted to evaluate the hypothesis that students get higher grades in the co-teaching classroom (taught by two teachers) as opposed to students in the one-teacher classroom. The result indicated that a significant difference existed between the two teaching approaches, $t(25.3)=3.42, p$ $<.05(95 \%$ CI $[3.15,12.4])$. This suggests that students who were part of the co-teaching group $(M=86.2, S D=$ 4.4) achieved, on average, higher grades than those who were taught by one teacher $(M=78.4, S D=8.6)$. The effect size was 1.11, suggesting a large effect. Table 2 summarizes these results.

Table 2. Effects of co teaching on student's score in L2 groups

\begin{tabular}{lllll}
\hline Co-teaching & One teacher & $t=(25.3)$ & $\mathrm{P}$ & $95 \% C I$ \\
\hline 86.2 & 78.4 & 3.42 & .002 & {$[3.15,12.4]$} \\
$(4.4)$ & $(8.6)$ & & & \\
\hline
\end{tabular}

Note: $p<.05 . N=34$. Standard deviations appear in parentheses below means. $\mathrm{CI}=$ confidence interval.

In other words, the results indicate that the students who were taught by the co-teaching method (experimental group) received higher grades in total when compared with students who were taught by one instructor (control group). This improvement in students' performance answers the research question positively. Because of co-teaching, EFL students who were exposed to several strategies showed significant enhancement in their overall academic performance. This promising improvement occurred because co-teaching assisted EFL learners to absorb the information at a pace that was comfortable for them. In other words, the multiple strategies of the co-teaching model can certainly develop students' understanding and could be a very useful method of teaching since it offers the students the same topics from different viewpoints and understandings.

\section{References}

Aliakbari, M., \& Bazyar, A. (2012). Exploring the Impact of Parallel Teaching on General Language Proficiency of EFL Learners. Pan-Pacific Association of Applied Linguistics, 16(1), 55-71.

Aliakbari, M., \& Nejad, A. (2010). Implementing a Co-Teaching Model for Improving EFL learners' Grammatical Proficiency. In International Conference "ICT for Language Learning" 3rd edition. Florence, Italy. Retrieved from http://conferencepixel-online.net/ICT4LL2010/

Aliakbari, M., \& Nejad, A. (2013). On the Effectiveness of Team Teaching in Promoting Learners' Grammatical Proficiency. Canadian Journal of Education, 36(3), 5-22.

Bacharach, N., Heck, T., \& Dahlberg, K. (2008). Co-Teaching In Higher Education. Journal of College Teaching \& Learning, 5(3), 9-16. https://doi.org/10.19030/tlc.v5i3.1298

Gately, S., \& Gately, F. (2001). Understanding co-teaching components. Teaching Exceptional Children, 33(4), 40-47 Gillespie, D. \& Israetel, A. (2008). Benefits of Co-Teaching in Relation to Student Learning. In 116th Annual Meeting of the American Psychological Association (pp. 1-7). Boston, Massachusetts. https://doi.org/10.1177/004005990103300406

Haynes, J. (2016). everythingESL: The K-12 ESL Resource from Judie Haynes. Everythingesl.net. Retrieved 12 October 2016, from http://www.everythingesl.net

\section{Copyrights}

Copyright for this article is retained by the author(s), with first publication rights granted to the journal.

This is an open-access article distributed under the terms and conditions of the Creative Commons Attribution license (http://creativecommons.org/licenses/by/4.0/). 